\title{
Side-by-side dual echoendoscope and ultrathin en- doscopy to facilitate EUS-ERCP biliary rendezvous
}

Endoscopic ultrasound (EUS)-guided biliary access is performed when standard endoscopic retrograde cholangiopancreatography (ERCP) techniques fail and for inaccessible papillae [1]. EUS rendezvous requires passage of the guide wire into the duodenum, with subsequent removal of the echoendoscope and insertion of a second endoscope to grasp the distal end of the wire. During echoendoscope withdrawal, the position of the guide wire is tenuous. We describe EUS rendezvous whereby passage of a small-caliber endo-

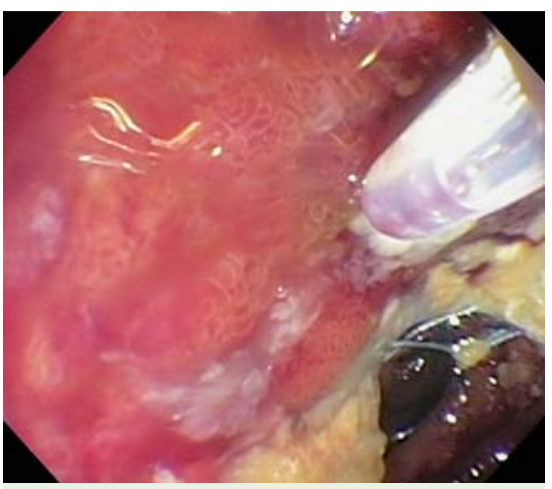

Fig. 1 Endoscopic image taken from within the previously placed gastroduodenal stent, showing extensive tumor infiltration. scope alongside the echoendoscope stabilizes the position of the guide wire.

A 67-year-old man presented with biliary and duodenal obstruction due to unresectable pancreatic cancer. An uncovered gastroduodenal stent was placed, but the papilla could not be identified through the interstices because of tumor infiltration ( Fig. 1). A linear echoendoscope (UC140P-AL5; Olympus America, Center Valley, Pennsylvania, USA) was used to achieve biliary access with a 19-gauge fine-needle aspiration needle (EUSN-3; Cook Endoscopy, Winston-Salem, North Carolina, USA). A 0.025-inch hydrophilic guide wire was then advanced and coiled within the duodenum. The echoendoscope was withdrawn. Unfortunately, looping during insertion of the duodenoscope resulted in the guide wire being dislodged from the duodenum and bile duct. The echoendoscope was reinserted with biliary access and duodenal passage of the guide wire again achieved. The echoendoscope remained in place to ensure the guide wire remained in position while a 5.4-mm endoscope (Olympus) was inserted alongside and passed into the duodenum ( $\bullet$ Fig.2). The wire was grasped with a pediatric biopsy forceps

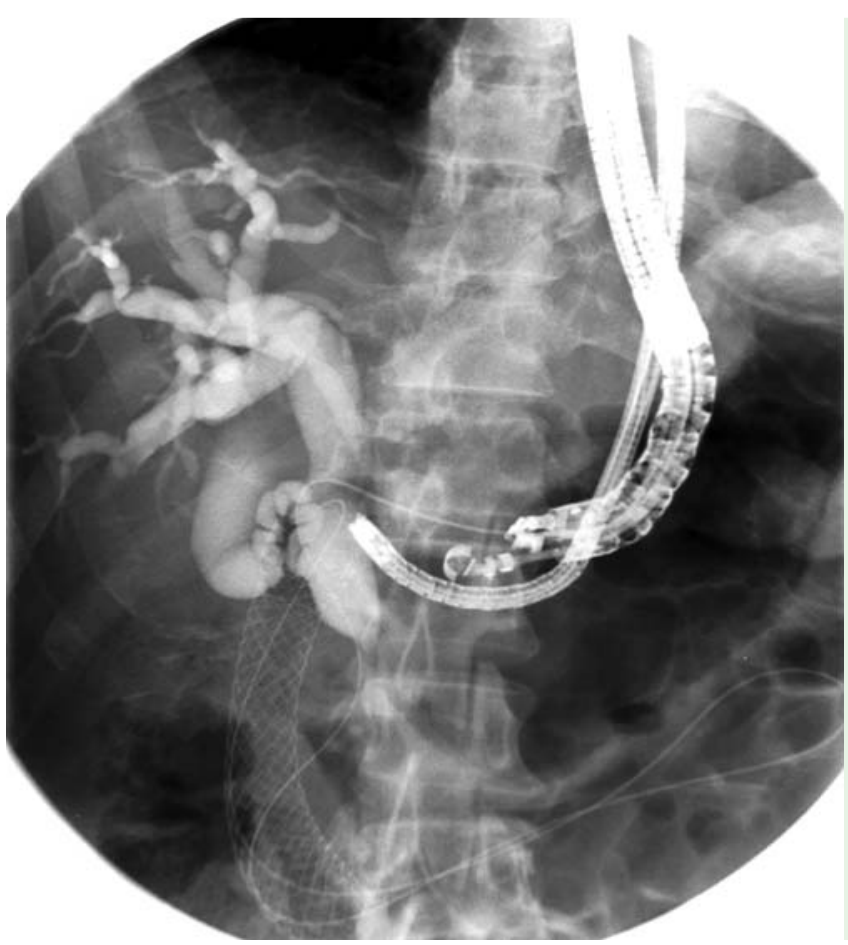

Fig. 2 Radiographic image showing the small-caliber upper endoscope passed alongside the echoendoscope. The endoscopic ultrasound (EUS) fineneedle aspiration (FNA) needle is within the biliary tree, and the guide wire is coiled within the lumen of the duodenal stent.

and the endoscope and wire were withdrawn followed by withdrawal of the echoendoscope, leaving both ends of the wire exiting the mouth. Using fluoroscopic guidance alone, gentle traction of the guide wire allowed balloon dilation of the stent interstices and biliary stricture and placement of a self-expandable metal stent ( $\bullet$ Fig. 3 ).

In type-II combined duodenal and biliary obstruction (as defined by Mutignani et al. [2]), the transpapillary approach often fails and EUS-guided drainage is the only
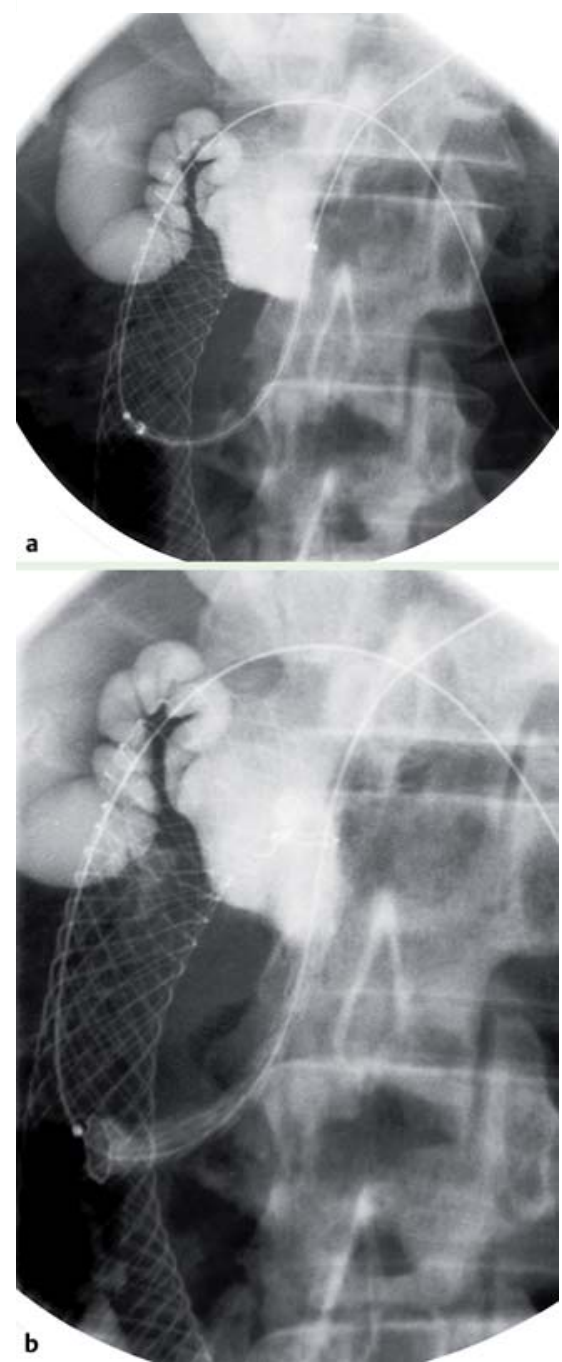

Fig.3 Radiographic images showing: a predeployed self-expandable metal stent in position across the stricture (note the absence of the endoscope); $\mathbf{b}$ deployed stent across the stricture, with the distal end within the duodenal lumen. 
endoscopic option to relieve jaundice [3] We believe this side-by-side dual endoscopic technique greatly facilitates EUSERCP rendezvous procedures as needed in this case.

\section{Endoscopy_UCTN_Code_TTT_1AR_2AK}

Competing interests: Olympus, ConMed, Cook, Boston Scientific (Dr. Baron); Olympus, Dr. Levy.

\section{T. H. Baron, M. J. Levy}

Division of Gastroenterology and Hepatology, Mayo Clinic, Rochester, Minnesota, USA

\section{References}

1 Gleeson FC, Levy MJ. Endoscopic ultrasound (EUS) guided access and therapy of pancreatico-biliary disorders. Minerva Gastroenterol Dietol 2008; 54: 151 - 160

2 Mutignani M, Tringali A, Shah SG et al. Combined endoscopic stent insertion in malignant biliary and duodenal obstruction. Endoscopy 2007; 39: 440-447

3 Baron TH. Management of simultaneous biliary and duodenal obstruction: the endoscopic perspective. Gut Liver 2010; 4: 50 56
Bibliography

Dol http://dx.doi.org/ 10.1055/s-0032-1306794

Endoscopy 2012; 44: E188-E189

(c) Georg Thieme Verlag KG

Stuttgart · New York

ISSN 0013-726X

Corresponding author

T. H. Baron, MD

Mayo Clinic

200 First Street SW

Rochester

MN 55905

USA

Fax: +1-507-2655-7612

baron.todd@mayo.edu 